\title{
Resilience amidst winds of change
}

Tiing Leong $\underline{A n g}^{1}$, FRCPEd, FAMS, Mahesh $\underline{C h o o l a n i}^{1}$, PhD, FRCOG, Kian Keong $\underline{\text { Poh }}^{2}$, FRCPEd, FACC

$\mathrm{T}$ he COVID-19 pandemic and the impact of climate change were headline news in the year 2021. Despite the challenges arising from the impact of COVID-19 and manpower constraints at the Singapore Medical Journal (SM), we continue to forge on. We are pleased to share that the 2020 Journal Impact Factor (IF) for the SMJ increased from 1.359 in 2019 to 1.858 in 2020, and the latest five-year IF is 2.053. The Journal's IF has progressively increased over recent years, ${ }^{(1)}$ and this is the highest it has been since the $S M$ / was first published in 1960. As we enter the year 2022 with a sense of quiet optimism, we would like to take this opportunity to update the SM/ community about key developments and share our aspirations.

We have continued to highlight subject matters that are of topical interest, especially for our local medical community, even as we remain an international medical journal that accepts quality academic submissions from across the world. Some of these recent publications addressed diverse topics such as mentoring and competency, ${ }^{(2)}$ medical professionalism, ${ }^{(3)}$ responding to the challenges of COVID-19, ${ }^{(4)}$ COVID-19 vaccine-related concerns, ${ }^{(5)}$ and colon cancer screening at a younger age. ${ }^{(6)} \mathrm{A}$ highlight of the $S M$ J has been our Continuing Medical Education (CME) articles with online CME quizzes that are pre-approved for the Singapore Medical Council Category 3B CME programme. Our Practice Integration and Lifelong Learning (PILL) articles serve the needs of our primary care colleagues in this area. To meet the needs of trainees and generalists in the hospital setting, a new CME series, Problem-Solving for Acute and Critical Care (PACC), will be launched in 2022.

In addition, we have increased our presence in social media. ${ }^{(7)}$ We can now interact with readers on Twitter, Facebook and Linkedln. We have also been recording selected articles for podcasts, although this was temporarily halted owing to COVID-19 concerns and logistical constraints. For original and review papers, we are highlighting the profiles of first authors (or senior authors) to increase their visibility. ${ }^{(8.9)}$ We are continually looking for high-quality, novel scientific papers with an impact on clinical practice.

We recognise that having a short turnaround time (TAT) from submission to review, editorial decision-making and publication is extremely important for the authors who submit articles to the $S M$ J. It is also crucial for our readers so that the information that reaches them is not outdated. There have been logistical challenges at the SMJ that resulted in TAT delays in previous years, but with the dedicated combined efforts of the editorial board members and editorial staff, significant progress has been made to shorten the TAT. The $S M$ / is currently also looking into other methods to improve efficiency and reduce our TAT, such as outsourcing operational matters. These changes will hopefully unfold in the coming year.

The $S M$ / will not rest on its laurels; we seek to constantly improve and be relevant to our medical community. We are thankful to the Editorial Board members, reviewers and editorial staff for their efforts in the past year. We would also like to thank the authors who have chosen to publish with us. We hope to count on your continued support in 2022.

\section{REFERENCES}

1. Poh KK. Increase in impact factor for the SMJ. Singapore Med J 2018; 59:345

2. Natarajan L, Gosavi AT, Wataganara T, et al. Mentoring a surgical team towards procedural competence in the early learning curve for selective fetoscopic laser photocoagulation. Singapore Med J 2020; Sep 21. [Epub ahead of print]

3. Ang TL. Professionalism in medical practice. Singapore Med J 2021; 62:107-8.

4. Ang TL, Li JW, Vu CKF, et al. Chapter of Gastroenterologists professional guidance on risk mitigation for gastrointestinal endoscopy during COVID-19 pandemic in Singapore. Singapore Med J 2020; 61:345-9.

5. Ho JS, Sia $\mathrm{CH}$, Ngiam JN, et al. A review of COVID-19 vaccination and the reported cardiac manifestations. Singapore Med J 2021. [Epub ahead of print]

6. Ang TL, Yeoh KG. Is it time to lower the colorectal cancer screening age in average-risk adults in Singapore? Singapore Med J 2021; 62:617-9.

7. Ng CL, Poh KK. Singapore Medical Journal in the age of social media. Singapore Med J 2020; 61:501-2.

8. Panday VB, Shabbir A, Kuntjoro I, et al. Long-term effects of bariatric surgery on cardiovascular risk factors in Singapore. Singapore Med J 2021; 62:472-5.

9. Leong WYA, Ngiam JN, Tan RS, Lim SL, Poh KK. Controversies and discrepancies in the effect of dietary fat and cholesterol on cardiovascular risk. Singapore Med J $2021 ; 62: 56-62$ 